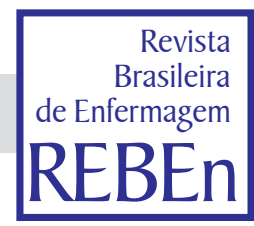

REVISÃO

\title{
Assistência de enfermagem ao potencial doador de órgãos em morte encefálica*
}

\author{
Nursing assistance to the potential organ donor with brain death
}

Atención de enfermería al potencial donante de órganos en muerte encefálica

\author{
Nancy Ramos Guetti', Isaac Rosa Marques' \\ 'Universidade de Santo Amaro, Faculdade de Enfermagem. São Paulo, SP
}

Submissão: 15/10/2007

Aprovação: 20/12/2007

\section{RESUMO}

O objetivo deste estudo foi descrever a atuação do enfermeiro na assistência para manutenção fisiológica de um potencial doador de órgãos. Trata-se de uma revisão bibliográfica não-estruturada Que considerou publicações correntes, tendo por base os materiais da Associação Brasileira de Transplantes de Órgãos e Associação de Medicina Intensiva Brasileira. Os resultados do estudo estão organizado $s$ de acordo com os seguintes tópicos: aspectos éticos relacionados à retirada de órgãos e tecidos, repercussões fisiopatológicas da morte encefálica (ME), sinais clínicos e tecnológicos da ME e a assistência de enfermagem na manutenção fisiológica do potencial doador de órgãos. Conclui-se que é essencial Que o enfermeiro tenha conhecimentos sobre as possíveis alterações fisiopatológicas resultantes da ME. Ao colocar em prática tais conhecimentos, seu papel contribuirá para mudanças no cenário dos transplantes.

Descritores: Transplantes; Morte encefálica; Cuidados intensivos; Cuidados de enfermagem.

\section{ABSTRACT}

This study aimed at describing nurse's activities in the assistance for the physiological maintenance of potential organ donors. This is a non-structured bibliographic review that considered current publications having as basis the publications of the Brazilian Organ Transplant Association and of the Brazilian Intensive Medicine Association. Results are organized according to the following structure: ethical issues related to organ and tissue removal, physiological repercussions of brain death (BD), clinical and technological signs of $\mathrm{BD}$, and nursing assistance in the physiological maintenance of potential organ donors. It was concluded that it is essential for the nurse to have enough knowledge about possible physiological alterations resulting from BD. When that knowledge is put into practice, nurse's role will contribute for changes in transplants scenario.

Descriptors: Transplants; Brain death; Intensive care; Nursing care.

\section{RESUMEN}

Este estudio objetivo describir las actividades del enfermero en la atención para la manutención fisiológica de potenciales donantes de órganos. Es una revisión bibliográfica no estructurada en la cual se hay considerado las publicaciones actuales de la Asociación Brasileña de Transplantes de Órganos e la Asociación Brasileña de Medicina Intensiva. Los resultados están estructurados como se sigue: aspectos éticos relacionados a la remoción de órganos y tejidos, repercusiones fisiológicas de la muerte encefálica (ME), señales clínicos y tecnológicos de la ME y la atención de enfermería en la manutención fisiológica de potenciales donadores. Se hay concluido Que es esencial que el enfermero tenga conocimientos sobre las posibles alteraciones resultantes de la ME. Al colocar sus conocimientos en práctica, el rol de lo enfermero contribuirá para cambios en lo escenario de los transplantes.

Descriptores: Transplantes; Muerte encefálica; Cuidados intensivos; Atención de enfermería. 


\section{INTRODUÇÃO}

O conceito de morte não é estan@ue, embora as funções cardíacas e pulmonares sejam reconhecidas há séculos como essenciais para a sobrevivência.

Com o avanço de estudos, das técnicas de ressuscitação e de suporte vital, a atividade cerebral veio definir a vida e a morte do indivíduo, vinculando assim a morte a critérios neurológicos, evoluindo para o Que conhecemos atualmente como Morte Encefálica (ME).

A determinação de ME varia de país para país. No Brasil, o Conselho Federal de Medicina, na resolução CFM no $1.346 / 91$, define morte encefálica como a parada total e irreversível das funções encefálicas, de causa conhecida e constatada de modo indiscutível $^{(1,2)}$.

Inicialmente, deve-se definir a causa do coma para declarar que um paciente esteja em ME. As causas mais freqüentes são o traumatismo crânio-encefálico (TCE), no contexto de acidentes automobilísticos ou agressões; hemorragia subaracnóidea, ligada à ruptura de aneurisma; lesão difusa do cérebro após parada cárdiorespiratória revertida; hemorragia cerebral espontânea maciça; grandes lesões isquêmicas, e em menor número, as meningoencefalites e encefalites fulminantes e a falência hepática aguda (por hepatite viral ou tóxica ou raramente, Síndrome de Reye) $)^{(3)}$.

O diagnóstico de ME é determinado pelo exame clínico neurológico, a partir da ausência evidente de reflexos do tronco cerebral em um paciente em coma, excluída Qualquer causa reversível do mesmo, tais como: intoxicação exógena, uso terapêutico de barbitúricos, alterações metabólicas e hipotermia.

O diagnóstico de ME deverá ser seguido de manutenção prolongada do corpo através de ventilação mecânica e outras medidas com a possibilidade de doação de órgãos ${ }^{(4)}$.

No ano de 2006, foram notificados 5.627 casos de potenciais doadores no Brasil, sendo Que apenas 1.109 se tornaram doadores efetivos. As principais causas da não efetivação da doação são: a não autorização familiar ( 1.539 casos), a contra-indicação médica (2.173 casos), a ME não confirmada (1 86 casos) e infra-estrutura inadeeuada $\left(62\right.$ casos) ${ }^{(5)}$. Como pode ser observado pelos dados apresentados, a contra-indicação médica é a Que apresenta maior taxa para a não efetivação da doação de órgãos; As situações Que determinam a contra-indicação absoluta da captação de todos os órgãos de um potencial doador são: a presença de anticorpos contra o vírus da imunodeficiência adeuirida, a presença de infecções virais de evolução lenta, a história de uso de drogas endovenosas, a presença de neoplasias (exceto Quando primária do sistema nervoso central) e de sepse bacteriana ${ }^{(4)}$.

Um único potencial doador em boas condições, poderá beneficiar, através de transplantes de diversos órgãos e tecidos, mais de 10 pacientes. Por isto deverá ser conduzido e manuseado com o mesmo empenho e dedicação Que Qualquer outro paciente da UTI(6). Mesmo Que um potencial doador se torne um doador efetivo, não significa que todos os órgãos poderão ser aproveitados. Para isso é necessário garantir uma adequada preservação e posterior viabilidade destes órgãos até a extração.

O enfermeiro de terapia intensiva deve conhecer as alterações fisiológicas decorrentes da ME, para Que, junto com a equipe médica, possa conduzir o manuseio adequado do potencial doador.

Tendo em mente o contexto apresentado acima, este estudo tem como objetivo descrever a importância da atuação do enfermeiro na assistência para manutenção fisiológica de um potencial doador em ME.

\section{METODOLOGIA}

O presente trabalho é uma revisão bibliográfica não-estruturada, onde foram considerados os materiais existentes e pertinentes ao tema em estudo. A fonte destes dados foi constituída voluntariamente, considerando publicações consagradas (livrostextos), materiais de curso de sociedades (ABTO - Associação Brasileira de Transplantes, e AMIB - Associação de Medicina Intensiva Brasileira), artigos de periódicos específicos sobre o tema.

Estes materiais foram apreciados por meio de leitura analítica $\mathrm{e}$ de síntese, classificando-os de acordo com categorias temáticas.

As categorias temáticas resultantes para atingir o objetivo proposto foram: Aspectos Éticos Relacionados à Retirada de Órgãos e Tecidos; Repercussões Fisiopatológicas da ME; Sinais Clínicos/ Tecnológicos da ME; Assistência de Enfermagem na Manutenção Fisiológica do Doador.

\section{RESULTADOS E DISCUSSÃO}

\section{Aspectos Éticos Relacionados à Retirada de Órgãos e Tecidos}

A Legislação Brasileira sobre doação de órgãos vem sofrendo intensa modificação nos últimos anos. Desde a primeira lei, aprovada em 1968, Que teve a capacidade de iniciar a discussão sobre o comportamento das pessoas frente à doação, até a Lei no 9.434 de 04 de fevereiro de 1997, Que inclui no cotidiano de todos os brasileiros o termo "doação presumida", tivemos uma ampla mudança no comportamento social ${ }^{(7)}$.

A Lei n ${ }^{\circ} 9.434$ permite a disposição gratuita de tecidos/órgãos/ partes $(\mathrm{T} / \mathrm{O} / \mathrm{P})$ do corpo humano em vida ou post mortem para fins de transplante desde que sejam realizados por estabelecimentos de saúde e por equipes médico-cirúrgicas de remoção e transplantes, previamente autorizadas pelo Ministério da Saúde, sendo Que a retirada post mortem de T/O/P deverá ser precedida do diagnóstico de $\mathrm{ME}$, constatada e registrada por dois médicos não participantes das equipes de transplantadores. O consentimento presumido foi revogado pela Lei $n^{\circ} 10.211$ de 23 de março de 2001, definindo Que a retirada de T/O/P de pessoas falecidas dependerá da autorização do cônjuge ou parente maior de idade, obedecida a linha sucessória reta ou colateral, até o $2^{\circ}$ grau inclusive, firmada em documento subscrito por duas testemunhas presentes à verificação da morte ${ }^{(8)}$.

\section{Repercussões Fisiopatológicas da ME}

A ME é um processo complexo Que altera a fisiologia de todos os sistemas orgânicos. Recentemente foi reconhecido Que ela envolve uma série de perturbações neuro-humorais cíclicas que incluem alterações bioquímicas e celulares que conduzem a disfunção múltipla de órgãos, repercutindo na Qualidade do órgão transplantado. Tanto as alterações iniciais Quanto as tardias influem na viabilidade dos órgãos ao comprometer sua perfusão, aumentando 
a lesão isQuêmica ${ }^{(9)}$.

A ME representa o processo final de progressão da isquemia cerebral Que evolui no sentido rostrocaudal até envolver regiões do mesencéfalo, ponte e bulbo, culminando com a herniação cerebral através do forâmen magno. O momento Que precede a herniação cerebral é marcado por extremas elevações da Pressão Intracraniana (PIC), acompanhada da tríade de Cushing, Que representa o esforço final do organismo na tentativa de manter a perfusão cerebral. A falência desse mecanismo promove a progressão da isQuemia Que, ao atingir o bulbo, interrompe a atividade vagal, levando à resposta autonômica simpática maciça, chamada de "tempestade autonômica”. Essa estimulação simpática desenfreada tem curta duração e caracteriza-se por taQuicardia, hipertensão, hipertemia e aumento acentuado do débito cardíaco. A gravidade dessas alterações está associada com a velocidade de instalação da hipertensão intracraniana e da herniação cerebral. Subseqüentemente, a tempestade autonômica cessa e o resultado é a perda do tônus simpático com profunda vasodilatação e depressão da função cardíaca, Que, se não tratadas, devem progredir para assistolia em torno de 72 horas $^{(10)}$.

\section{Alterações Cardiovasculares}

A intensa liberação de catecolaminas durante a descarga autonômica produz grande vasoconstrição, Que acarreta hipertensão arterial, taquicardia e aumento da demanda de oxigênio do miocárdio, podendo causar isquemia e necrose miocárdica, além de arritmias cardíacas. Logo após a descarga autonômica, segue-se um período de extrema vasodilatação, com hipotensão arterial grave sendo esta a alteração fisiopatológica mais grave da ME. A vasodilatação produz grande aumento da capacitância do sistema vascular, produzindo hipovolemia relativa. A hipovolemia absoluta é conseQüência das perdas sangüíneas pelo trauma, da reanimação inadequada do doador, do uso de tratamento osmótico para hipertensão intracraniana, do diabetes insipidus, além da diurese osmótica causada pela hiperglicemia e dos efeitos da hipotermia sobre a diurese $\mathrm{e}^{(10)}$.

\section{Alterações Pulmonares}

O pulmão é muito susceptível aos eventos Que se seguem à ME. Durante o período de intensa descarga adrenérgica o sangue é redistribuído e ocorre um aumento do retorno venoso ao ventrículo direito o Qual aumenta rapidamente seu débito, aumentando o fluxo pulmonar. Simultaneamente a pressão de átrio esQuerdo está elevada devido a vasoconstrição periférica intensa de tal forma Que a pressão hidrostática capilar é muito aumentada promovendo ruptura de capilares com edema intersticial e hemorragia alveolar. Tais alterações manifestam-se com o desequilíbrio ventilação perfusão e hipoxemia ${ }^{(9)}$.

\section{Alterações Endócrinas}

A falência progressiva do eixo hipotalâmico-hipofisário evolui para um declínio gradual e inexorável das concentrações hormonais, principalmente do hormônio antidiurético (ADH). Diabetes insipidus ocorre em aproximadamente $80 \%$ desses pacientes e caracteriza-se por grandes volumes de diurese hiposmolar, com hipovolemia secundária, hipernatremia e hiperosmolaridade sérica. É importante causa de hipotensão e hipoperfusão tecidual, produzindo inúmeros distúrbios eletrolíticos além da hipernatremia, Que contribuem para o desenvolvimento de disritmias cardíacas e depressão miocárdica ${ }^{(10,1)}$.

Diminuições bruscas nos níveis de triiodotironina $\left(\mathrm{T}_{3}\right)$ são constatadas logo após a ME e têm sido implicadas na redução da contratilidade cardíaca, com depleção de fosfatos de alta energia e mudança do metabolismo aeróbico para anaeróbico. Isso contribui para a piora da acidose metabólica e da perfusão tecidual dos órgãos do doador.

A secreção de insulina também está comprometida, podendo produzir hiperglicemia. Aliado a isso, há o aumento da resistência periférica à insulina.

\section{Alterações Hepáticas e da Coagulação}

No fígado ocorre depleção dos estoQues de glicogênio e redução da perfusão sinusoidal hepática. A lesão do tecido cerebral libera tromboplastina tecidual e outros substratos ricos em plasminogênio. Esses fatores de coagulação, acidose e hipotermia favorecem o desenvolvimento de coagulação intravascular disseminada $^{(10)}$.

\section{Alterações de Temperatura}

A regulação hipotalâmica da temperatura é perdida com a ME. A vasodilatação extrema típica da síndrome, associada à inabilidade de tremer para produzir calor, além da infusão de grandes volumes de fluidos não aquecidos, resulta em diminuição de temperatura de forma muito rápida. A hipotermia induz a diversos efeitos deletérios, como disfunção cardíaca, disritmias, coagulopatia, desvio da curva de dissociação da hemoglobina para a eseuerda e diurese induzida pelo frio ${ }^{(10)}$.

\section{Sinais Clínicos e Tecnológicos da ME}

O diagnóstico de ME é feito através da análise da história médica e dos achados ao exame físico e do eventual recurso a exames complementares (obrigatórios pela legislação brasileira).

Uma vez estabelecida a causa do coma, Que possa ser registrada e Que tenha caráter de irreversibilidade deverão ser realizados exames clínicos para detectar a ausência de função encefálica.

O início do exame clínico deverá ser em um paciente hemodinamicamente estável. Logo todos os recursos de terapia disponíveis devem ser empregados para a adeQuação hemodinâmica.

Devem se afastar as situações de hipotensão grave, hipotermia, alterações metabólicas e o uso de sedativos ou bloqueadores da junção neuro-muscular, Que podem alterar a avaliação do exame neurológico comprometendo o diagnóstico ${ }^{(1)}$.

O exame clínico deverá ser repetido em no mínimo duas ocasiões, preferencialmente por médicos diferentes e em intervalos de tempo de no mínimo seis horas.

O diagnóstico de ME é diferenciado de acordo com a idade, sendo:

- de 7 dias a 2 meses de idade (incompletos): dois EEG com intervalo de 48 hs.

- de 2 meses a I ano (incompleto): dois EEG com intervalo e 24 hs.

- de I ano a 2 anos (incompletos): o tipo de exame é facultativo. No caso de EEG são necessários dois registros com intervalo mínimo de 12 horas. 
Em pacientes acima desta idade é necessário apenas a realização de um exame complementar, de escolha facultativa.

O exame clínico consiste em uma tríade diagnóstica: coma profundo arreativo e aperceptivo, ausência de reflexos de tronco encefálico e constatação da apnéia(2).

Coma: o paciente em ME dever estar em coma arreativo e arresponsivo. Para o diagnóstico de ME só interessa a arreatividade supraespinal. Desta forma, a presença de reflexos osteotendinosos (reflexos profundos), cutâneos-abdominais, cutâneo-plantar em flexão ou extensão, ereção peniana reflexa, arrepio, reflexos flexores de retirada dos membros inferiores ou superiores, reflexo tônico cervical e outras manifestações de caráter medular espinal não invalidam a situação de ME. Deve-se estimular o paciente não apenas nos membros, mas também na face, evitando-se o erro diagnóstico nos pacientes com lesões medulares altas.Deve-se testar bilateralmente com compressão da região supra-orbitária e das apófises estilódes (estimulo axial). E das bases ungueais

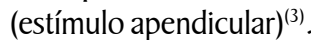

Ausência de reflexos de tronco encefálico: tais reflexos representam a capacidade de integração encefálica. Os testes necessários para demonstrar a falência do tronco encefálico levam apenas alguns minutos para serem realizados, mas sua importância é fundamental para o prosseguimento da avaliação diagnóstica de ME. Devem ser testados os reflexos ${ }^{(3)}$ :

- Fotomotor: pálpebras fechadas inicialmente; abrir as pálpebras e fazer incidir feixe de luz em cada uma das pupilas. As pupilas devem estar fixas, sem resposta fotomotora ou consensual ao estímulo luminoso direto. O tamanho pupilar deve estar entre o tamanho médio (4 a $6 \mathrm{~mm}$ ) e o dilatado (6 a $8 \mathrm{~mm}$ ).

- Córneo-palpebral: abrem-se as pálpebras e com a ajuda de um instrumento fino e delicado (SWAB) é realizado um estímulo direto da córnea, próximo à esclera. Na ME não ocorrerá o fechamento reflexo das pálpebras.

- Óculo-cefálico: Abrindo-se forçadamente as pálpebras, é realizado a movimentação rápida e vigorosa no sentido horizontal e vertical, com observação da ausência de movimentos oculares.("Olhos de Boneca"). Este teste está contra-indicado nos pacientes com suspeita ou existência de lesão cervical.

- Óculo-vestibular: Antes do exame deve-se certificar que não há obstrução do canal auditivo por cerúmen ou QualQuer outra condição Que dificulte ou impeça a correta realização do exame. Com a cabeceira do leito elevada a $30^{\circ}$, é realizada a infusão de 50 $\mathrm{ml}$ de líquido frio no conduto auditivo externo. Deve-se observar por um minuto a ausência de movimentos oculares. O teste deve ser realizado bilateralmente e deve-se aguardar ao menos cinco minutos entre um ouvido e outro.

- Traqueal: este reflexo pode ser testado através da aspiração da cânula orotrąueal ou trąueostomia , da fricção da trąuéia ou da colocação de abaixador de língua na região posterior da língua. Na ME não ocorrerá o reflexo da tosse ou náusea.

Constatação da apnéia: Para a realização do teste de apnéia a temperatura do paciente deve ser igual ou maior Que $36,5^{\circ} \mathrm{C}$, a pressão arterial sistólica deve ser maior Que 90 mmHg (com ou sem uso de drogas vasoativas), a correção do diabetes insipidus, com uso de vasopressina e infusão salina. Procede-se com a adequação do ventilador mecânico, onde o paciente deve se hiperoxigenado por 10 minutos com $\mathrm{FiO}_{2}$ de $100 \%$, garantindo um
$\mathrm{PO}_{2}$ acima de $200 \mathrm{mmHg}$. Colhe-se uma gasometria arterial, instalase oxímetro de pulso e retira-se o paciente da ventilação mecânica, mantendo-se um catéter de $\mathrm{O}_{2}$ no interior da cânula com fluxo contínuo de 6litros/minuto. O paciente deverá permanecer assim por 10 minutos consecutivos, com observação rigorosa a beira do leito Quanto a presença de movimentos respiratórios. Decorridos os 10 minutos, colhe-se outra gasometria arterial e conecta-se novamente o paciente ao ventilador. $\mathrm{O}$ teste será positivo se a $\mathrm{PaCO}_{2}$, ao final do exame, for igual ou superior a $60 \mathrm{mmHg}$. O teste é dito negativo se houver movimento respiratório durante sua realização e é inconclusivo se não houver movimento respiratório durante a realização do exame mas também não forma atingidos os níveis esperados de $\mathrm{PaCO}_{2}$. Se o paciente apresentar instabilidade hemodinâmica ou dessaturação, com hipoxemia e arritmia secundária o teste deve ser interrompido, deve-se colher uma nova gasometria arterial e reinstituir a ventilação mecânica. Se o nível de $\mathrm{PaCO}_{2}$ for maior ou igual a $60 \mathrm{mmHg}$, o teste é dito positivo, mesmo com sua interrupção. Caso contrário, o teste é inconclusivo $^{(2,3,11)}$.

Há estudos que contestam a utilização do "teste de apnéia" como parte integrante de protocolos para o diagnóstico de ME, referindo Que o mesmo pode induzir ou colaborar para a morte encefálica a Qual pretende-se constatar. Referem como efeitos nocivos determinados pelo teste de apnéia a hipóxia (não prevenida em todos os casos apesar de precauções aconselhadas), a hipercapnia (inegável, já Que é o próprio objetivo do teste, e que provoca piora da hipertensão intracraniana nesses pacientes), acidose respiratória abrupta (inevitável, e determinante de graves conseQüências sobre a função cardiovascular), hipotensão severa (capaz de provocar colapso circulatório intracraniano irreversível induzindo a morte das células neuronais) e parada cardíaca fatal ${ }^{(12)}$. Obviamente estas constatações estão relacionadas às condições e peculiaridades na realização do teste.

Como já dito, no Brasil a avaliação da ME deve ser acompanhada de exames complementares, mesmo no caso de pacientes não doadores. Estes servem para corroborar o diagnóstico.

Os exames complementares devem demonstrar de forma inequívoca a ausência de circulação intracraniana, ou a falência da atividade elétrica ou a cessação da atividade metabólica cerebral ${ }^{\prime \prime}$.

Os exames realizados para detectar a ausência de circulação intracraniana são:

- Angiografia Cerebral: o resultado deverá demonstrar a ausência do preenchimento arterial por 30 segundos ou mais ao nível da bifurcação carotídea ou do polígono de Willis após injeção de contraste iodado sob pressão nas artérias carótidas e vertebrais. A principal desvantagem do método é o risco, pela injeção repetida de contraste, de nefrotoxicidade e perda dos órgãos (raro) ${ }^{(3)}$.

- Cintilografia Radioisotópica: observa-se, por captação de imagens através de gama câmara, a ausência de fluxo sanguíneo acima do tronco encefálico após injeção rápida de albumina marcada por radioisótopo (tecnésio). Esse exame tem a desvantagem de não avaliar o sistema vertebrobasilar ${ }^{(2)}$.

- Doppler Transcraniano: este exame é de fácil realização e custo operacional baixo; pode ser realizado a beira do leito, com Doppler pulsátil de $2 \mathrm{MHz}$ onde realiza-se a insonação de duas artérias intracranianas - cerebral média através da janela temporal e vertebral ou basilar através da janela suboccipital ou senão cerebral 
média e oftálmica através da janela transorbitária. Os sinais descritos em caso de ME são o padrão de ausência de fluxo diastólico ou reverberação (há fluxo somente durante a sístole ou senão fluxo retrógrado durante a diástole) e padrão de picos sistólicos breves. ̇̀ um exame complementar Que tem 91,3\% de sensibilidade e 100\% de especificidade e se não houver captação de sinal durante o exame, ele não confirma nem afasta o diagnóstico pois em até $20 \%$ dos doentes não é possível insonação dos vasos pela janela temporal ${ }^{(2)}$.

- Ressonância Magnética (RM) de crânio: o uso de fósforo intravenoso (P3 I) com a imagem da RM mostra uma completa ausência de ATP e um intenso sinal de fósforo inorgânico, sugerindo Que o fluxo está ausente ${ }^{(7)}$.

Os exames Que avaliam a atividade elétrica cerebral são:

- EEG: a ausência de atividade elétrica no EEG continua a ser a observação auxiliar mais comumente citada no estabelecimento da ME. Não se detecta atividade elétrica acima de $2 \mathrm{~V} / \mathrm{mm}$ - com filtros ajustados para $70 \mathrm{~Hz}$ e $0, \mathrm{I}$ a 0,3 segundos - durante pelo menos 30 minutos. As principais limitações se dão pelo surgimento de interferências - artefatos - em ambientes como as UTIs; e à persistência de atividade elétrica residual em alguns pacientes ${ }^{(3)}$.

- Potencial Evocado Auditivo de Tronco Encefálico: o exame se constitui em um estímulo auditivo aplicado e a sua atividade no tronco encefálico é obtida com técnicas eletroencefalográficas. O Padrão de ondas obtido e a modificação de algumas dessas ondas dão a integridade ou não do tronco encefálico. Os resultados não são afetados com o uso de sedativos, podendo ser, então, utilizada em pacientes com resíduos de sedativos. É importante lembrar Que em pacientes com diminuição de audição pode-se obter resposta alterada e Que a presença de fratura em osso temporal deve ser excluída previamente $\mathrm{e}^{(7)}$.

Para a avaliação da atividade metabólica cerebral temos dois exames:

- Extração Cerebral de Oxigênio: através da monitorização de oximetria de bulbo jugular, a extração cerebral de oxigênio consiste na diferença entre a saturação arterial de oxigênio e saturação venosa do bulbo jugular, onde os valores normais estão entre 24 e $42 \%$. Valores abaixo de $10 \%$ sugerem morte cerebral ${ }^{(2)}$.

- Tomografia por Emissão de Pósitrons (PET): a monitorização das reações Químicas do cérebro em tempo real fornecem uma informação cinética valiosa e não simplesmente estrutural; entretanto, sua utilização nessa aplicação atualmente é limitada pelo custo dos radiofármacos usados e eQuipamento ${ }^{(13)}$.

\section{Assistência de Enfermagem na Manutenção Fisiológica do Doador}

Como já descrito, a ME pode causar múltiplos efeitos deletérios sobre o organismo, resultando em instabilidade cardiovascular, desarranjos metabólicos e hipoperfusão tecidual. É importante que se tenha um amplo conhecimento destas possíveis complicações, possibilitando o reconhecimento precoce e conseQüente manuseio para a preservação dos órgãos.

O objetivo básico na manutenção do potencial doador pode ser resumido na regra dos $10 / 100^{(14)}$ :

- Hemoglobina $>10 \mathrm{~g} / \mathrm{dl}$

- Pressão Venosa Central (PVC) $>10 \mathrm{mmHg}$

- Pressão arterial sistólica $>100 \mathrm{mmHg}$

- Dopamina $<10 \mu \mathrm{g} / \mathrm{Kg} / \mathrm{min}$
- Débito urinário $>100 \mathrm{ml} /$ hora

$-\mathrm{PaO}_{2}>100 \mathrm{mmHg}$

É de responsabilidade da equipe de enfermagem realizar o controle de todos os dados hemodinâmicos do potencial doador. Para isso é necessário que o enfermeiro desta equipe possua conhecimentos a respeito das repercussões fisiopatológicas próprias da $\mathrm{ME}$, da monitorização hemodinâmica, e repercussões hemodinâmicas, advindas da reposição volêmica e administração de drogas vasoativas ${ }^{(6)}$.

O Quadro I demonstra , em um roteiro sistemático das condutas frentes às possíveis seQüelas da $\mathrm{ME}^{(6,14)}$.

Um controle hídrico rigoroso deve ser realizado, pois baseadas neste, atitudes terapêuticas serão tomadas. Além disso, as drogas vasoativas deverão ser rigorosamente controladas, de acordo com a resposta hemodinâmica deste paciente.

Atentar-se ao paciente em uso de Nitroprussiato de Sódio, pois seu gotejamento deve ser rigorosamente controlado e a pressão arterial deve estar monitorizada, de maneira invasiva ou não, por um membro da equipe de enfermagem deverá controlar a pressão arterial de forma intensiva.

A reposição volêmica deverá ser realizada através de uma veia calibrosa periférica, lembrando Que as drogas vasoativas devem ser administradas em veias centrais, sempre utilizando-se de vias exclusivas, evitando-se o uso concomitante de medicações e/ou reposição volêmica rápida pelas mesmas.

A hiperglicemia deve ser controlada realizando-se dosagens seriadas de glicose sangüínea. Se isto não for possível, o enfermeiro deve orientar a equipe a realizar controle de glicemia capilar, no mínimo, de Quatro em Quatro horas. Se houver persistência do distúrbio, os intervalos de controle devem ser diminuídos.

O controle dos distúrbios hidroeletrolíticos também deve ser realizado através de dosagem seriada dos eletrólitos e o enfermeiro deve estar atento a QualQuer alteração.

A equipe de enfermagem deve estar atenta a Quaisquer distúrbios da coagulação. Estas alterações podem se manifestar através de sinais menores, como mudança da coloração da diurese (hematúria), gengivorragias ou sangramento persistente em locais de punções vasculares.

Precauções universais devem ser tomadas para imperdir as complicações infecciosas.

A monitorização eletrocardiográfica deve ser realizada com o intuito de se detectar presença de arritmias, para um possível intervenção o mais precocemente possível.

O controle e a manutenção da temperatura é função exclusiva da enfermagem. No aQuecimento do potencial doador utilizam-se soluções aQuecidas $\left(37^{\circ}-38^{\circ} \mathrm{C}\right)$, para lavagens gástricas e vesicais, para administração endovenosa, a instalação e controle de cobertores térmicos e a nebulização aQuecida.

A manutenção de uma adeQuada ventilação e oxigenação deve ser monitorada através de coleta de material para dosagem dos gases sanguíneos e do controle dos parâmetros do ventilador. $\mathrm{O}$ enfermeiro envolvido com a manutenção do potencial doador deve possuir conhecimento do equilíbrio ácido-básico e da fisiologia respiratória, a fim de assistir adequadamente a este paciente.

Na ocorrência de uma parada cardíaca, o enfermeiro, junto com o médico, deve instituir as manobras ressuscitadoras básicas $\mathrm{e}$ avançadas. 


\begin{tabular}{|c|c|c|}
\hline SeQüelas & Causa & Manuseio \\
\hline $\begin{array}{l}\text { Descarga simpática: hipertensão } \\
\text { arterial e taquicardia }\end{array}$ & - $\quad$ herniação do tronco encefálico. & - $\begin{array}{c}\text { Expectante. Nitroprussiato de sódio }(1-5 \mu \mathrm{g} / \mathrm{kg} / \mathrm{min}) \text {.B- } \\
\text { bloqueador }\end{array}$ \\
\hline Hipotensão & $\begin{array}{ll}\text { - } & \text { Choque neurogênico } \\
\text { - } & \text { Hipovolemia } \\
\text { - } & \text { Falência endócrina }\end{array}$ & $\begin{array}{l}\text { - Reposição volêmica: Ringer lactato, soluções hipotônicas } \\
\text { (aquecidas), evitar colóides; para manter PVC: } 10-12 \mathrm{mmHg} \text { e } \\
\text { PCP: } 14-18 \mathrm{mmmHg} \text {. } \\
\text { Vasopressores: Dopamina < } 10 \mu \mathrm{g} / \mathrm{kg} / \mathrm{min} ; \text { Dobutamina < } \\
15 \mu \mathrm{g} / \mathrm{kg} / \mathrm{min} \text {; Norepinefrina: } 0,1-2 \mu \mathrm{g} / \mathrm{kg} / \mathrm{min}+\text { Dopamina: } 1 \text { - } \\
3 \mu \mathrm{gg} / \mathrm{min} . \\
\text { - Reposição de } \mathrm{T}_{3} \text {, cortisol e AVP em dose pressora }(1-2 \mathrm{U} / \mathrm{h})\end{array}$ \\
\hline Arritmias/ Bradicardia & $\begin{array}{ll}\text { - } & \text { Lesão cerebral isquêmica. } \\
\text { - } & \text { Hipotermia } \\
\text { - } & \text { Distúrbio HE e AB } \\
\text { - } & \text { Isquemia miocárdica } \\
\end{array}$ & $\begin{array}{ll}- & \text { resistente à atropina } \\
\text { - } & \text { Corrigir distúrbios HE e AB } \\
\text { - } & \text { Drogas } \beta \text {-adrenérgicas/ marcapasso. }\end{array}$ \\
\hline Hipoxemia & $\begin{array}{ll} & \text { Lesão SNC } \\
\text { - } & \text { Insuf. Pulmonar } \\
\text { - } & \text { Ventilação inadeQuada }\end{array}$ & $\begin{array}{l}\text { - ventilação mecânica: } \mathrm{PaO}_{2}>100 \mathrm{mmHg} ; \mathrm{PaCO}_{2}: 35-40 \mathrm{mmHg} \text {; } \\
\text { pH: } 7,35-7,45 ; \text { PEEP }<7,5 \mathrm{cmH}_{2} \mathrm{O} ; \mathrm{FiO}_{2}<40 \%\end{array}$ \\
\hline Hiperglicemia & $\begin{array}{ll}\text { - } & \text { Resistência insulínica } \\
\text { - } & \text { Estresse } \\
\text { - } & \text { Sobrecarga de glicose }\end{array}$ & - $\quad$ Insulina IV contínua (5-7 U/hora) \\
\hline Diabetes insipidus & - $\quad$ Falência hipotálamo-hipofisária. & $\begin{array}{ll}\text { - } & \text { reposição volêmica hiposmótica } \\
\text { - } & \text { AVP em dose antidiurética }(0,1-0,4 \mathrm{U} / \mathrm{h}) \\
\text { - } & \operatorname{DDAVP}(0,03-0,15 \mathrm{U} / \mathrm{kg} \text {, intranasal } 8 / 8 \mathrm{~h})\end{array}$ \\
\hline Coagulopatia & - $\quad$ Lesão SNC & $\begin{array}{ll}- & \text { Plasma fresco } \\
\text { - } & \text { Plaquetas } \\
\text { - } & \text { Crioprecipitado } \\
\end{array}$ \\
\hline Anemia & Hemorragia/Hemodiluição & - $\quad$ Concentrado de hemácias para manter $\mathrm{Hb}>10 \mathrm{~g} / \mathrm{dl}$ \\
\hline Infecções & Trauma/Ventilação prolongada & $\begin{array}{ll} & \text { Antibióticos se houver infecção } \\
\text { - } & \text { Profilaxia Pré-Tx é controversa } \\
\end{array}$ \\
\hline Hipotermia & $\begin{array}{ll}\text { - } & \text { Perda da regulação central } \\
\text { - } & \text { Falência endócrina } \\
\text { - } & \text { Infusão excessiva de soluções } \\
& \text { hídricas não-aquecidas. }\end{array}$ & $\begin{array}{ll}\text { - } & \text { Manter a temperatura central }>35^{\circ} \mathrm{C} \\
\text { - } & \text { Cobertor térmico } \\
\text { - } & \text { Soluções IV aquecidas } \\
\text { - } & \text { Nebulização aquecida na Ventilação mecânica. }\end{array}$ \\
\hline
\end{tabular}

PVC: Pressão Venosa Central; PCP: Pressão de Capilar Pulmonar; $T_{3}$ : Triiodotironina; AVP: arginina-vasopressina; DDAVP: desmopressina; SNC: Sistema Nervos Central; HE: hidroeletrolítico; AB: Acidobásico; IV: intravenosa; Tx: transplante.

\section{Quadro I. SeQüelas da morte encefálica e seus manuseios.}

Quando for instituída a terapêutica de reposição hormonal, o enfermeiro deve realizar um controle rigoroso dos dados hemodinâmicos a fim de verificar a resposta a esta terapia.

\section{CONCLUSÃO}

A manutenção do potencial doador inclui, desde o seu reconhecimento e posterior confirmação, o pleno conhecimento de todas as formalidades legais envolvidas no processo, a prevenção, detecção precoce e manuseio imediato das principais complicações advindas da ME para Que os órgãos possam ser retirados e transplantados nas melhores condições funcionais possíveis.

O enfermeiro deve estar capacitado a identificar tais alterações fisiopatológicas para que, junto com a equipe de saúde, possa instituir medidas terapêuticas adeQuadas.

Diante da crescente escassez de doadores e de órgãos em condição satisfatória, é essencial Que se otimize o cuidado devido aos pacientes em ME para Que os mesmos, uma vez Que se tornem em doadores efetivos, possa haver melhor aproveitamento de todos os órgãos possíveis de serem transplantados.

Considerando Que a enfermagem assume responsabilidade natural de cuidados aos pacientes nestas condições, há uma tendência de menor investimento cuidativo por parte da equipe de enfermagem, principalmente Quando não há definição sobre a doação. Quando a doação é formalizada, talvez não haja tempo nem condições ideais de manutenção de certos órgãos. Com isto, o impacto na realização de certos transplantes decorre desta forma de abordagem por parte do enfermeiro ou da equipe de enfermagem.

Com este trabalho foi possível reunir um corpo de conhecimentos necessários para Que uma melhor assistência de enfermagem possa ser providenciada. De porte destes conhecimentos a enfermagem pode contribuir para melhorar o cenário dos transplantes, o Qual não é muito favorável no cenário brasileiro. 


\section{REFERÊNCIAS}

1. Conselho Federal de Medicina. Resolução. CFM n. 1346/91. Regulamentação do diagnóstico de morte encefálica. Ética médica. São Paulo (SP): CREMESP; 1996.

2. Associação de Medicina Intensiva Brasileira. Morte encefálica. Curso de imersão em terapia intensiva neurológica. $4^{\mathrm{a}} \mathrm{ed}$. São Paulo (SP): AMIB; 2005.

3. André C, Morte cerebral - diagnóstico e suporte clínico. In: André C, Freitas GR. Terapia intensiva em neurologia e neurocirurgia - métodos de monitorização e situações especiais. Rio de laneiro (RI): Revinter; 2002. p. 303-23.

4. Knobel E. Condutas no paciente grave. $2^{\mathrm{a}}$ ed. São Paulo (SP): Atheneu; 1998.

5. Associação Brasileira de Transplantes de Órgãos. Registro Brasileiro de Transplantes. Reg Bras Transpl 2006; 12(2): 28-31.

6. Araújo S, Cintra EA, Bachega EB. Manutenção do potencial doador de órgãos. In: Cintra EA, Nishide VM, Nunes WA. Assistência de enfermagem ao paciente gravemente enfermo. São Paulo: Atheneu; 2005. p. 443-56.

7. Sardinha LAC, Dantas Filho VP. Morte encefálica. In: Cruz I, editor. Neurointensivismo. São Paulo (SP): Atheneu; 2002. p. 235-59.
8. Brasil. Lei n. 9434 de 04 de fevereiro de 1997. Dispõe sobre a remoção de órgãos, tecidos e partes do corpo humano para fins de transplante e tratamento e dá outras providências. Brasília (DF): ANVISA; 1997.

9. D'Império F. Morte encefálica, cuidados ao doador de órgãos e transplantes de pulmão. RBTI 2007; 19(1): 74-84.

10. Rech TH, Rodrigues Filho EM. Manuseio do potencial doador de múltiplos órgãos. RBTI 2007; 19(2): 197-204.

II. Vilibor RA. Diagnóstico de morte encefálica. Curso de formação de coordenadores intra-hospitalar de transplante. São Paulo (SP): ABTO; 2007.

12. Coimbra CG. Apnéia na morte encefálica. São Paulo (SP): UNIFESP; 200 I. [citado em 26 set 2007]. Disponível em: URL: http://www.unifesp.br/dneuro/apnea.htm

13. Gauger GE. Declaração de morte cerebral. In: Andrews BT. Tratamento intensivo em neurocirurgia. Rio de Janeiro (RI): DiLivros; 2004. p. 229-33.

14. Caldeira Filho M, Westphal GA. Manual prático de medicina intensiva. São Paulo (SP): Segmento; 2005. 